\title{
On Social Behavior From the Perspective of Meme
}

\author{
Xianze $\mathrm{Wu}^{1,2, *}$ and Hui Chen ${ }^{1}$
}

\author{
${ }^{1}$ School of Foreign Languages, Changshu Institute of Technology \\ ${ }^{2}$ College of Foreign Studies, Guilin University of Technology \\ *Corresponding author. Email: moiwxz@126.com
}

\begin{abstract}
Meme is a cultural information unit. memes can be divided into good and bad, right and wrong. A good meme likes a gene that can be inherited generation by generation. Pro-social behavior, just like gene, can be replicated, imitated, and spread, so as to promote interpersonal relationship and the harmonious development of the society. However, bad meme just like the "virus", can cause bad influence on our society. Angry behavior, just like the "virus", can be spread to our mind one by one, which does great harm to our physical and mental health, and causes many negative effects on our society.
\end{abstract}

Keywords: Meme, Gene, Virus, Pro-social behavior, Angry behavior.

\section{INTRODUCTION}

The term "meme" has a long history, which is a core word in "memetic theory". It was first mentioned in the book The Selfish Gene by Richard Dawkings, a famous zoologist and behavioral ecologist at Oxford University in the United Kingdom [1]. The word meme is originated from the word "gene", which is derived from Greek and means "a thing to be imitated". Richard Dawkings in his book The Selfish Gene proposed Meme is a unit of cultural evolution, and those languages, cultural customs, ideas, or social behaviors that are constantly copied and spread all belong to meme.

Bruce Edmonds, a professor at Manchester Metropolitan University in the United Kingdom, mentioned in The Poverty of Memetic Prompts that memes can be divided into broadly defined memes and narrowly defined memes. In a broad sense, memes refer to imitating communication or other social phenomena that are imitated, while in a narrow sense, memes refer to the similarities between memes and genes. This broad defined memetic theory has been recognized by a great number of memetic scholars [2]. Blackmore believes that any piece of information can become a meme as long as it can be "copied" through the process of "imitation" [3].

At present, scholars at home and abroad have done a lot of research on memes and pragmatics, but few have done research on human social behavior.
According to Ziran He, a Chinese scholar, memes can be divided into good and bad, right and wrong, but some memes, such as certain beliefs and behaviors, may be neutral, not good or bad, which exist because they are themselves memes, having been spreading widely among people. A successful meme, like a successful duplication of genes, has three characteristics, which is longevity, fertility, and fidelity of duplication [4]. Although some memes are neutral, any behavior, if imitated and spread by others, will inevitably bring some positive or negative influence on others or society. The paper will deal with the influence of people's social behavior from the perspective of memes as well as the social influence it brings about.

\section{PEOPLE'S SOCIAL BEHAVIOR: PRO- SOCIAL BEHAVIOR AND ANGRY BEHAVIOR}

People's social behavior is very complicated and incomprehensible both from an individual perspective and from a social perspective. People's social behavior will be elaborated from two aspects: pro-social behavior and angry behavior.

\subsection{Pro-social Behavior}

Pro-social behavior is also called positive social behavior. It refers to all behaviors that meet social expectations and are beneficial to others, groups or society. 
People often do similar behaviors in common social life, such as helping others, sharing with others, cooperating with others, being concern with others, and sympathizing with others, etc. Pro-social behavior is an important basis on which a good relationship between people in the process of communication is maintained, which is of great significance to the development of an individual in a lifetime. It includes not only the altruistic behaviors which are embodied in voluntarily helping others without expecting any return, but also the behaviors of helping others in an attempt for a certain purpose or a return.

\subsection{Angry Behavior}

Angry behavior, according to Derek Gatherer in 2002, is also called aggressive behavior. Based on a wrong premise, this behavior may not have a significant impact on others, but in most cases, it is extremely potentially harmful [5].

\section{PRO-SOCIAL BEHAVIOR FROM THE PERSPECTIVE OF MEME}

Memes are also divided into good and bad, or right and wrong. In the environment of pro-social behavior, a good meme will be imitated, copied and spread, which is so-called the successful meme. Its influence on prosocial behavior will be discussed from the perspective of the three characteristics of memes.

\subsection{Longevity of Memes}

The longevity of memes means that the memes stay in the meme library for a long time, that is, the memes can circulate on paper or in people's mind for a long time.

Taking respecting the old and loving the young as an example, there have been many famous aphorisms about respecting the old and loving the young since ancient times, such as Mencius's "care the old as they are your parents, and feed the young as they are your children"; Zhuangzi's "Failing to jump over the Beihai Sea With Mount Tai under your arm is because of your inability instead of your unwillingness, while having not broken a branch for the elderly is because of your unwillingness instead of your inability"; Stendhal's "Being respected when you grow old is the most beautiful privilege of the human spirit"; An Indian proverb says "You have no sympathy for the old man who fell to the ground, and there is no one to help you when you fall"; Makarenko's "Educating children by beating is just similar to the way in which the ape raise its offspring", and so on.

The reason why these famous aphorisms can be accepted by the world and will continue to be passed on from generation to generation is that these famous aphorisms can reflect personal qualities, family harmony and social friendship. People from generation to generation regard these famous aphorisms as a kind of guiding ideology for pro-social behavior, guiding people in actively engaging in their related social behaviors and helping realize certain values from it. In the meantime, these famous aphorisms are like memes. As long as someone will initiate putting these aphorisms into action, which is imitated and spread by others, these aphorisms can circulate in the human brain for a long time.

Therefore, this pro-social behavior of respecting the old and loving the young can continue to be carried forward, which thereby maintain the good relationship between people to a certain extent, further promote the harmonious development of society, and accelerate the civilization process of human society.

\subsection{The Fertility of Memes}

The fertility of memes refers to the rapid and wide spread of memes, which depends on to which extent they can be accepted by people and its survival value. In pro-social behavior, what people are interested in talking about is the behavior of helping others, which includes not only the behavior of helping others without expecting a return but also the behavior of helping others for a certain purpose. However, no matter what the purpose is, the result is to have helped others and freed them from a certain predicament.

This pro-social behavior has been accepted and imitated by people for generations. So, what makes this kind of behavior of helping others spread so quickly and so widely? Why are people advocating this kind of behavior of helping others?

Take Sima Guang's smashing the tank as an example. When seeing a child fall into a tank full of water, Sima Guang was wise and brave enough to smash the tank so that the child could be rescued in time. It has always been used as a typical example to teach children to do what is right and how to solve problems when they encounter problems. Generations of children have accepted this idea and tried to be a wise man by imitating him who do what is right. Like a genetic meme implanted in people's brain, Sima Guang's behavior has been rooted and germinated in the brain of generations of children.

Another example is the Wenchuan earthquake happening in Sichuan Province in China on May 12, 2008. Hardly had the Wenchuan earthquake happened when all walks of people around China began to plunge themselves into helping those people in disaster, trying their best to donate money or to offer labor. Batch after batch of volunteers have been involved in the rescue work. Even some enthusiastic people, having quit their jobs, joined the team of volunteers to help those affected by the disaster out of difficulties. Those volunteers 
helped the victims rebuild their homes and hoped that they can return to a stable life soon. The kind-hearted volunteers did all for those victims without expecting a return.

This positive social behavior that meets social expectations can be spread to the greatest extent in a very short time. This is because the memetic behavior of helping others has been accepted by people, who think that the memetic behavior of helping others has its real social value.

\subsection{The Fidelity of the Meme}

The fidelity of the meme refers to the fact that the memes tend to retain the original essence during the copying process, rather than remain unchanged. Human society is a complex society, where the relationship between people is also extremely complicated. In this kind of complex environment of social relationship, inner thoughts and feelings of people are complicated.

This fidelity of the meme also covers the various phenomena that appear in the environment of pro-social behaviors, which include sympathy, helping others, cooperation and other positive behaviors that are conducive to social harmony and development. The characteristic of the fidelity of the meme can be used to explain these specific behaviors.

When you first saw a child or an old man begging along the street, how did you feel? You might give them some change or something to eat. But some people will hesitate and wonder whether the beggars are liars or cheaters? If not, how can they help these beggars? To find out the truth, they may turn to police for help. These different ways of doing things will have different results, but there is something in common: the motivation is out of sympathy, which is caused by the memetic behavior of sympathy.

Another example is China's assistance to Africa, which has been lasting for more than 60 years. This assistance is characterized with two dimensions: change and unchanged. What remains unchanged is that China's assistance to Africa has always been based on mutual benefit; what has changed is that such mutual assistance policies, priorities, methods, etc. have been continuously changed and improved.

From the above, it is showed that the "mutual benefit" in China-Africa relations is an "essence", which has enabled China-Africa relations to be in a good state for so many years. However, the maintenance of this good relationship requires different measures be taken at different stages.

\section{ANGRY BEHAVIR FROM THE PERSPECTIVE OF MEME}

From the perspective of meme, according to Derek Gatherer, angry behavior is based on the wrong premise. This behavior may not have a significant impact on others, but in most cases, it is extremely potentially harmful.

In fact, people all know about the harmfulness of anger, and are very often reminded of its harmfulness. This kind of angry behavior results from a lack of rational thinking or an impulsive and reckless approach, which often brings bad moods and discordant interpersonal relationship to people. An important reason why people do this behavior is that even though they are dissatisfied with the actual situation, they are powerless and can do nothing. They have to do some abnormal behavior to release the angry emotions in their heart.

This seems to be an effective method, but in fact it is quite the opposite. Angry behavior will only make people even more angry. Like fire, it not only burns itself, but also spreads wildly on the grassland, finally turning into a sea of fire. When doing an angry behavior, people are really easy to become furious, like bursting into fire. From the perspective of memes, harmful memes spreading bad social phenomena. Angry behavior is like a "virus", infecting other people's brains or spreading to other people's brains. A person is infected by this virus, which will be parasitic in his brain. Later on, the infected person will spread this "virus" to other people or the next generation. This kind of "virus" has brought great harm to people's physical and mental health and has also caused a great impact on society, which is not conducive to harmonious coexistence between people or to the peaceful and stable development of society.

\section{CONCLUSION}

Memes can be good or bad, right or wrong. From the perspective of memes, this paper deals with the impact of people's social behavior from the perspective of memes as well as the social influence it brings about.

A favorable meme is like a good gene, the spread of which can promote the development of society. Prosocial behavior is like a good gene in the human brain. It can infect the brain of others. Pro-social behaviors, if imitated and spread by others, will be spread on a larger scale, promoting the establishment of good relationships between people and the harmonious development of society.

A harmful meme is like a virus. Their spread will cause undesirable phenomena in society. Angry behaviors are like "viruses" that infect other people's brains. It spreads from one to one. This "virus" has 
brought great harm to the people's physical and mental health and has also caused a great negative impact on society.

\section{ACKNOWLEDGMENTS}

The study is funded by the 2017 Annual Research Project of Guangxi Philosophy and Social Sciences Planning: Language Strategy Research in Guangxi under the background of "One Belt One Road" (Project Number: 17BYY003).

\section{REFERENCES}

[1] Derek Gatherer. The Spread of Irrational Behaviors by Contagion: An Agent MicroSimulation [J]. Journal of Memetics, 2002 (6).
[2] Yongping, Ran \& Ziran He. New Introduction to Pragmatics $[\mathrm{M}]$, Peking University Publishing House, 2009.

[3] Jianbo Luo \& Hongwu Liu. On the staged evolution and significance of the Chinese team's aid to Africa [J], west Asia and Africa Magazine. 2007(11): 25-30.

[4] Blackmore, S. The Meme Machine [M]. Oxford: Oxford University Press, 1999.

[5] Dawkins, R. The Selfish Gene [M] .New York: Oxford University Press. 1976.

[6] Edmonds, B. 2005. The revealed poverty of the gene-meme analogy - why memetics per se has failed to produce substantive results. Journal of Memetics, 2005. 